B.I. Kuznetsov, T.B. Nikitina, A.V. Voloshko, I.V. Bovdyj, E.V. Vinichenko, B.B. Kobilyanskiy

\title{
EXPERIMENTAL RESEARCH OF MAGNETIC FIELD SENSORS SPATIAL ARRANGEMENT INFLUENCE ON EFFICIENCY OF CLOSED LOOP OF ACTIVE SCREENING SYSTEM OF MAGNETIC FIELD OF POWER LINE
}

\begin{abstract}
Purpose. Experimental research of magnetic field sensors spatial arrangement influence on efficiency of closed loop active screening system by magnetic field of high voltage power lines developed a three-phase single-circuit high voltage power lines, creating a rotating magnetic field with the most complex space-time structure. Methodology. Optimal spatial arrangement of the magnetic field sensors is determined by solving the active magnetic field screening system synthesis problems with which the system provides the greatest efficiency of the active magnetic field shielding. Synthesis of active screening system is reduced to the problem of multi-criteria nonlinear programming with constraints in which calculation of the objective functions and constraints are carried out on the basis of Biot-Savart-Laplace law. The problem is solved by a stochastic multi-agent optimization by multiswarm of particles which can significantly reduce the time to solve it. Calculated arrangement of magnetic field sensors in a given space defined by the points at which the values of the corresponding components of the vector of magnetic induction take minimal values. Results. For the first time experimentally that changes in the position of the magnetic field sensors relative to their calculated position reduces the effectiveness of screening. The optimum position of the magnetic field sensors are the points at which the levels of the magnetic induction vector of projections orthogonal to the planes of the compensating coils are minimum values. Originality. For the first time invited to place sensors closed loop active screening system by magnetic field of high voltage power lines at the points where the calculated levels of corresponding projections of the magnetic induction vector orthogonal planes compensating windings are minimum values. Practical value. Practical recommendations for evidence-based selection of the spatial arrangement of the magnetic field sensors in a given area to ensure maximum efficiency of the active magnetic field screening system. References 14. figures 6.
\end{abstract}

Key words: power frequency magnetic field, high voltage power lines model, active screening system model, experimental research.

Проведено экспериментальное исследование влияния пространственного расположения датчиков магнитного поля на эффективность замкнутой системы активного экранирования магнитного поля линий электропередачи на разработанном макете трехфазной одноцепной воздушной линии электропередачи, создающей вращающееся поле с наиболее сложной пространственно-временной структурой. Экспериментально показано, что наибольщую эффективность имеет замкнутая система активного экранирования магнитного поля, у которой датчики магнитного поля пространственно расположены в расчетных точках, полученных при синтезе системы, в которых значения соответствующих компонент вектора магнитной индукции принимают минимальное значение. Библ. 14, рис. 6.

Ключевые слова: магнитное поле промышленной частоты, макет воздушной линии электропередачи, макет системы активного экранирования, экспериментальные исследования.

Introduction. Ministry of Fuel and Energy of Ukraine [1] in 2014 introduced regulatory levels of the magnetic field (MF) with a frequency of $50 \mathrm{~Hz}$. Many residential buildings and structures are located in the vicinity of overhead power lines so that the level of the magnetic field inside them exceeds these standards. The use of active screening systems can reduce the levels of magnetic fields to standard values and continue the operation of such buildings.

Analysis of existing active screening systems. In the systems of active screening of man-made magnetic field of industrial frequency [2-10] as the executive body they use special winding - active cables, the number of which is determined by the specifics of the problem being solved. Active screening system can include one, two, three, six, twenty-four or more windings. To control these coils they use a different number of magnetic field meters - magnetometers: one, two, three, six, twenty-four or more. Number of magnetometers usually equals to the number of controlled winding or number of windings pairs. In particular, with six coils type magnetometer three Helmholtz coils may be used, located in the center of the magnetic field shielding region [10] or six magnetometers disposed in respective planes and orthogonally oriented with respect to the control windings.
In the synthesis of closed systems of active shielding magnetic field, power transmission lines an important issue is to determine the position of the magnetic field sensors, in which the efficiency of the system has the greatest value. Typically, a closed system is configured in such a way that with the help of the given magnetic windings of the executive bodies to minimize the level of the magnetic field at the points of the installation of the magnetic field sensors. One approach to the definition of the position of the magnetic field sensors based on the solution of the active screening system synthesis problem of the magnetic field by providing the maximum efficiency of the system of active screening of the magnetic field. Synthesis of active screening system is reduced to the problem of multi-criteria linear programming with restrictions, in which calculation of the objective functions and constraints are carried out on the basis of the of Biot-Savart-Laplace low [11, 12]. The problem is solved by a stochastic multi-agent optimization by multiswarm of particles [13, 14] which can significantly reduce the time to solve it. Calculated arrangement of magnetic field sensors in a given space defined by the points at which the values of the corresponding components of the vector of magnetic induction take minimal values.

(C) B.I. Kuznetsov, T.B. Nikitina, A.V. Voloshko, I.V. Bovdyj, E.V. Vinichenko, B.B. Kobilyanskiy 
The goal of the work is the experimental study of the influence of the spatial arrangement of the magnetic field sensors on the efficiency of the closed system of the active screening of the magnetic field of power lines on the layout developed a three-phase single-circuit overhead transmission line, creating a rotating field with the most complex space-time structure.

The sketch of the transmission line layout, control windings, as well as the region of space in which the magnetic field must be shielded are shown in Fig. 1. Active screening system comprises two compensating winding forming the compensating magnetic field when current flows through it, generated by the control system (CS) in the magnetic field feedback signal function, that formed by the magnetic field sensors (FS) installed in the protected space. The CS receives power from the secondary power source.

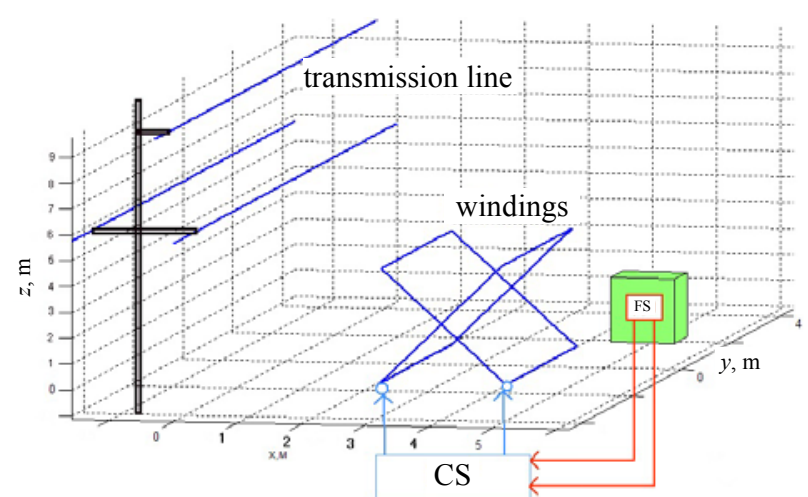

Fig. 1. Sketch of the active screening system layout

The coordinates of the spatial location and geometric dimensions of the compensation coils, as well as the parameters of the active screening system regulators determined on the basis developed in [11] the active screening system MF synthesis method in the course of solving multiobjective optimization problem. Fig. 2 shows the lines of equal levels of magnetic flux density with enabled active screening system.

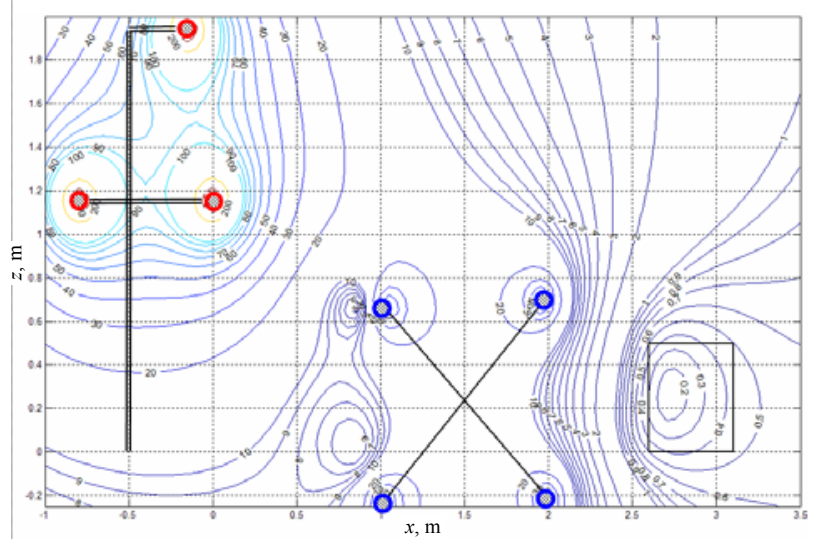

Fig. 2. Lines of equal levels of magnetic flux density with enabled active screening system

Note that the need to use two compensating windings due to the fact that the three-phase single-circuit transmission line creates an almost circular magnetic field. Fig. 3,a shows an exemplary travel time curve formed by the initial induction vector of the magnetic field generated by this power line. Therefore, to compensate for this source of magnetic field must have at least two compensation coil to generate a circular magnetic field.

Fig. 3, $b$ shows a locus formed by the vector of the magnetic field generated by the two compensating windings. As can be seen from this figure, by means of compensating windings creates a magnetic field that is close enough to the original to the magnetic field generated by power lines.

Fig. 3,c shown in the hodograph formed induction vector of the total magnetic field generated by power lines and compensating windings when the active screening system. As can be seen from this figure, the hodograph formed induction vector remaining after the screening of the active magnetic field system has an order of magnitude smaller unit compared to the initial magnetic field.

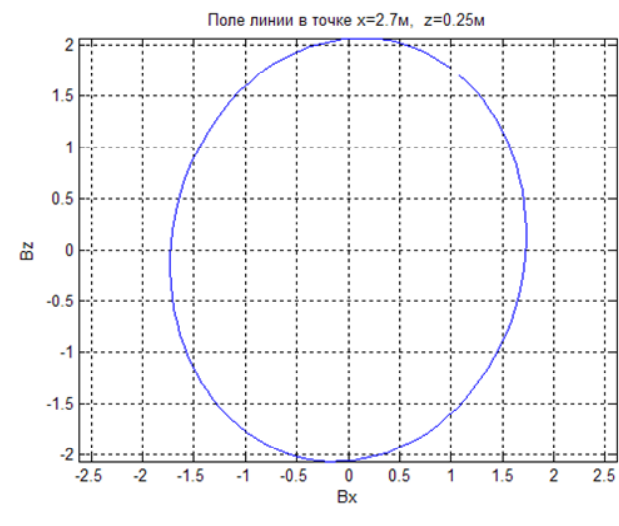

$a$

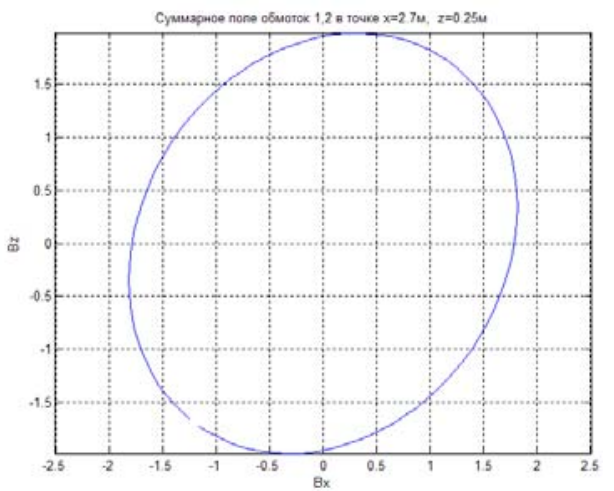

b

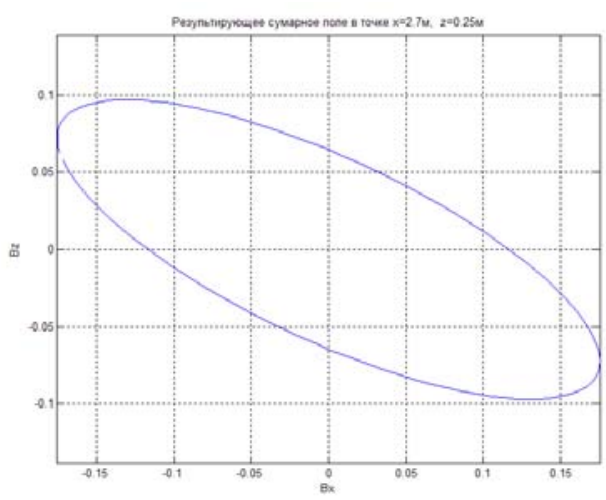

$c$

Fig. 3. Hodographs of vectors of magnetic flux density: a) the original, created by power lines; $b$ ) compensation windings; $c$ ) the total generated by the power lines and the system enabled 
Layout of the transmission line and active screening system. For experimental studies the layout of power transmission lines and active screening system is developed. Fig. 4, $a$ shows the external view of transmission line layout, and Fig. $4, b$ shows the external view of the compensation system layout. This Figure shows the compensation coils and magnetic field sensors.
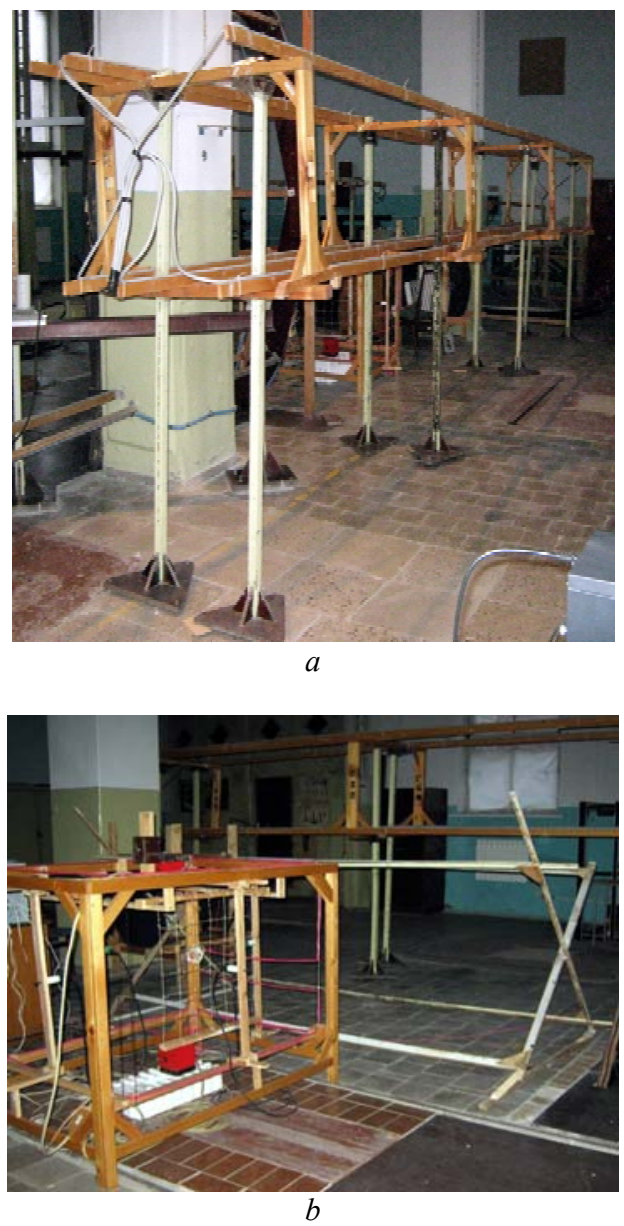

Fig. 4. External view of the layout:

a) transmission line; $b$ ) compensation system

These mock-ups were carried out pre-experimental studies to verify the adequacy of the mathematical models of the magnetic field on the basis of the Biot-SavarLaplace law $[11,12]$ the real processes occurring in models of transmission lines and compensating windings active screening system. As shown by experimental studies of models of transmission lines and compensating windings at different currents and different modes of operation, the deviation of the experimental values of the magnetic induction generated by power lines layout and compensating windings of calculated made by the method of [11] do not exceed $7 \%$.

The results of experimental investigations. Let us now consider the experimental study of the active screening system. The system has two independent magnetic field sensors in which the channels are closed current control compensation windings. First, we consider the experimental study of the active screening system when magnetic field sensors are arranged in the reference points of the space in which it is necessary to shield the magnetic field. These calculated points correspond to points at which the values of the corresponding components of the vector of magnetic induction take a minimum value. To determine these points first solved the problem of synthesis of active screening system. The initial parameters for the synthesis of the system are the parameters of power line - operating current, the geometry and the number of wires, the location of the transmission line with respect to the protected space, as well as the size of the protected area and the characteristic value of the magnetic field, which should be achieved as a result of screening. The result of the synthesis system is the number, shape, spatial arrangement, wiring diagram, currents compensation coils, as well as the resulting value of the magnetic field at the points of the protected area, as well as the parameters of the control system controls. Based on the resultant distribution system during the synthesis of the resultant magnetic field in this area are the points at which the values of the corresponding components of the vector of magnetic induction take minimal values.

Fig. 5, $a$ shows the surface distribution of the original magnetic field power transmission line in the middle section of the space and the surface magnetic field distribution-enabled system, and Fig. 5, $b$ shows the surface level of the compensation magnetic field induction system such baseline magnetic field of the power line.

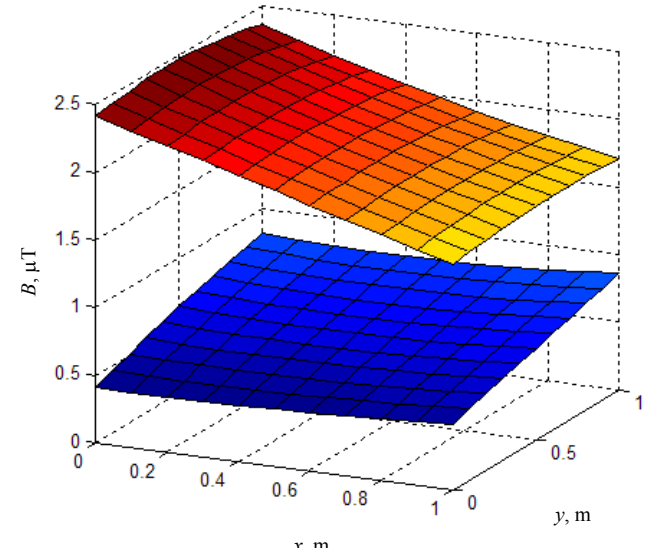

$a$

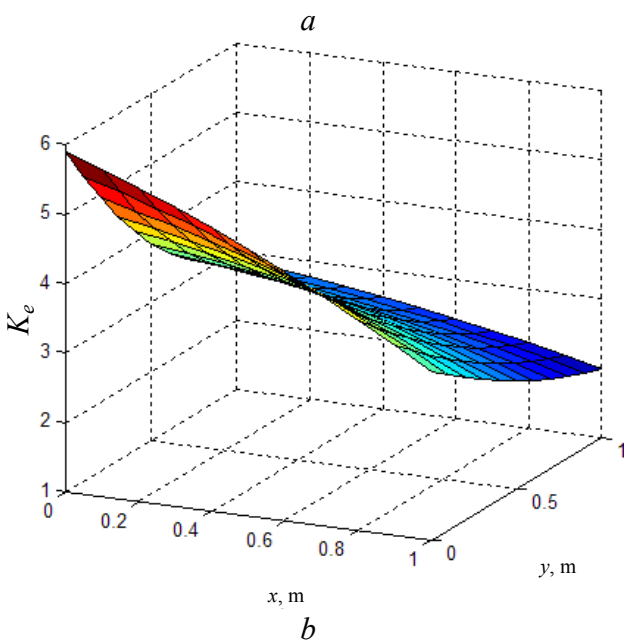

Fig 5. Surfaces of distribution: $a$ ) the magnetic flux density of the initial magnetic field and the magnetic field of power line with enabled system; $b$ ) the level of compensation of the magnetic flux density using the system 
Thus, when the system level active shielding of magnetic flux density in the considered region remains practically constant and is not greater than $0.5 \mu \mathrm{T}$, and the level of compensation of the magnetic field is more than $5 \mu \mathrm{T}$.

Note that the deviation of the experimental values of the magnetic flux density layout enabled active screening system from the calculated obtained in [11] does not exceed $10 \%$. Moreover, these variations are mainly due to inexact installation of the magnetometer, and the error operation controls open and closed control channels.

Fig. 6 shows the same distribution surface, as in Fig. 5 when placed in a magnetic field sensors central area shielding. With this arrangement, the sensor system has the greatest shielding effectiveness in the central part of the screening space - precisely where the magnetic field sensors are arranged. However, with this arrangement, the sensor system is active shielding has a higher level of residual magnetic induction in virtually all areas where it is necessary to shield the magnetic field.
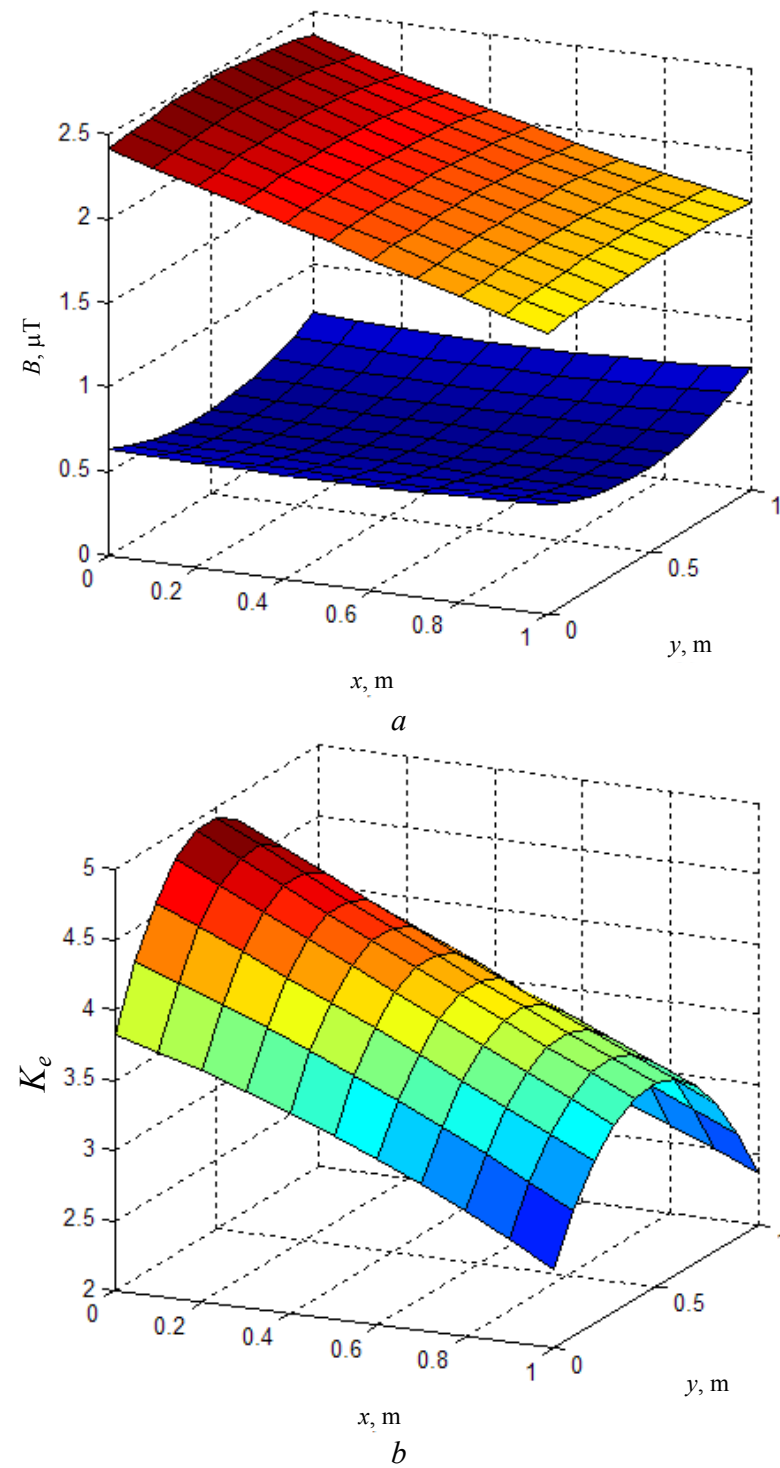

Fig. 6. Surfaces of distribution: $a$ ) the magnetic flux density of the initial magnetic field and the magnetic field of power line with enabled system; $b$ ) the level of compensation of the magnetic flux density by the system when placing field sensors in the central area of the screening

\section{Conclusions.}

Thus, it is experimentally found that the change of the position of magnetic field sensors relative to their calculated position reduces the efficiency of the screening system. The optimum position of the magnetic field sensors is the points at which the levels of projections of the magnetic flux density vector orthogonal to the planes of the compensating coils have minimum values.

\section{REFERENCES}

1. Pravila ulashtuvannya electroustanovok. Vyd. 3, pererob. $i$ dop [Electrical Installation Regulations. 3rd edition, revised and enlarged]. Kyiv, Minpalyvenergo of Ukraine Publ., 2010. 736 p. (Ukr).

2. Active Magnetic Shielding (Field Cancellation). Available at: http://www.emfservices.com/afcs.html (accessed 10 September 2012).

3. Beltran H., Fuster V., García M. Magnetic field reduction screening system for a magnetic field source used in industrial applications. 9 Congreso Hispano Luso de Ingeniería Eléctrica (9 CHLIE), Marbella (Málaga, Spain), 2005, pp. 84-99.

4. Celozzi S., Garzia F. Active shielding for powerfrequency magnetic field reduction using genetic algorithms optimization. IEE Proceedings - Science, Measurement and Technology, 2004, Vol.151, no.1, pp. 2-7. doi: 10.1049/ipsmt:20040002.

5. Ter Brake H.J.M., Wieringa H.J., Rogalla H. Improvement of the performance of a mu -metal magnetically shielded room by means of active compensation (biomagnetic applications). Measurement Science and Technology, 1991, Vol.2(7), pp. 596-601. doi: 10.1088/0957-0233/2/7/004.

6. Yamazaki K., Kato K., Kobayashi K. MCG Measurement in the environment of active magnetic shield. Neurology and Clinical Neurophysiology, 2004, Vol. 40, pp. 1-4.

7. Celozzi S. Active compensation and partial shields for the power-frequency magnetic field reduction. Conference Paper of IEEE International Symposium on Electromagnetic Compatibility. Minneapolis (USA), 2002, Vol.1, pp. 222226. doi: 10.1109/isemc.2002.1032478.

8. Shenkman A., Sonkin N., Kamensky V. Active protection from electromagnetic field hazards of a high voltage power line. HAIT Journal of Science and Engineering. Series B: Applied Sciences and Engineering, Vol. 2, Issues 1-2, pp. 254-265.

9. Ter Brake H.J.M., Huonker R., Rogalla H. New results in active noise compensation for magnetically shielded rooms. Measurement Science and Technology, 1993, Vol. 4, Issue 12, pp. 1370-1375. doi: 10.1088/0957-0233/4/12/010.

10. Kazuo Kato, Keita Yamazaki, Tomoya Sato, Akira Haga, Takashi Okitsu, Kazuhiro Muramatsu, Tomoaki Ueda, Masahito Yoshizawa. Shielding effect of panel type active magnetic compensation. IEEJ Transactions on Fundamentals and Materials, 2005, Vol. 125, Issue 2, pp. 99-106. doi: 10.1541/ieejfms.125.99.

11. Rozov V.Yu., Reutskyi S.Yu. Pyliugina O.Yu. The method of calculation of the magnetic field of three-phase power lines. Tekhnichna elektrodynamika, 2014, no.5, pp. 11-13. (Rus). 
12. Nikolova N.K., Bakr M.H. Electromagnetics I. Matlab Experiments Manual for EE2FH3. Department of Electrical and Computer Engineering McMaster University, 2012. 96 p. 13. Clerc M. Particle Swarm Optimization. London, ISTE Ltd., 2006. 244 p. doi: 10.1002/9780470612163.

14. Gazi V., Passino K.M. Swarm Stability and Optimization. Springer, 2011. 318 p. doi: 10.1007/978-3-642-18041-5.

Received 15.09.2016

B.I. Kuznetsov ${ }^{1}$, Doctor of Technical Science, Professor, T.B. Nikitina ${ }^{2}$, Doctor of Technical Science, Professor,

A.V. Voloshko ${ }^{1}$, Candidate of Technical Science,

I.V. Bovdyj ${ }^{1}$, Candidate of Technical Science,
E.V. Vinichenko ${ }^{1}$, Candidate of Technical Science,

B.B. Kobilyanskiy ${ }^{1}$, Candidate of Technical Science, Associate

Professor,

${ }^{1}$ State Institution «Institute of Technical Problems of Magnetism of the NAS of Ukraine», 19, Industrialna Str., Kharkiv, 61106, Ukraine, phone+38050 5766900, e-mail: bikuznetsov@mail.ru ${ }^{2}$ Kharkov National Automobile and Highway University, 25, Petrovskogo Str., Kharkov, 61002, Ukraine, e-mail: tatjana55555@gmail.com

\section{How to cite this article:}

Kuznetsov B.I., Nikitina T.B., Voloshko A.V., Bovdyj I.V., Vinichenko E.V., Kobilyanskiy B.B. Experimental research of magnetic field sensors spatial arrangement influence on efficiency of closed loop of active screening system of magnetic field of power line. Electrical engineering \& electromechanics, 2017, no.1, pp. 16-20. doi: 10.20998/2074272X.2017.1.03. 